\title{
Reestablishment of Redox Homeostasis in the Nociceptive Primary Afferent as a Mechanism of Antinociception Promoted by Mesenchymal Stem/Stromal Cells in Oxaliplatin-Induced Chronic Peripheral Neuropathy
}

\author{
Anna Lethicia L. Oliveira, ${ }^{1}$ Gisele G. L. Santos, ${ }^{1}$ Renan F. Espirito-Santo, ${ }^{1}$ \\ Gessica Sabrina A. Silva, ${ }^{2}$ Afrânio F. Evangelista, ${ }^{1}$ Daniela N. Silva, ${ }^{3}$ Milena B. P. Soares, ${ }^{1,3,4}$ \\ and Cristiane Flora Villarreal $\mathbb{D D}^{1,2}$ \\ ${ }^{1}$ Gonçalo Moniz Institute, Oswaldo Cruz Foundation, 40296-710, Brazil \\ ${ }^{2}$ College of Pharmacy, Federal University of Bahia, 40170-290, Brazil \\ ${ }^{3}$ SENAI Institute of Innovation in Advanced Health Systems (ISI SAS), University Center SENAI/CIMATEC, 41650-010, Brazil \\ ${ }^{4}$ National Institute of Science and Technology for Regenerative Medicine (INCT-REGENERA), Rio de Janeiro, RJ, Brazil \\ Correspondence should be addressed to Cristiane Flora Villarreal; cfv@ufba.br
}

Received 12 August 2020; Revised 23 November 2020; Accepted 19 December 2020; Published 7 January 2021

Academic Editor: Hirotaka Suga

Copyright (c) 2021 Anna Lethicia L. Oliveira et al. This is an open access article distributed under the Creative Commons Attribution License, which permits unrestricted use, distribution, and reproduction in any medium, provided the original work is properly cited.

\begin{abstract}
Painful neuropathy is a common adverse effect of oxaliplatin (OXL), a platinum-derivative chemotherapeutic agent. Oxidative stress and mitochondrial dysfunction are key factors contributing to the development of OXL-induced peripheral neuropathy (OIPN). Based on the antioxidant and antinociceptive properties of mesenchymal stem/stromal cells (MSC), the present study tested the hypothesis that MSC induce antinociceptive effects during OIPN by promoting regulation of redox environment and mitochondrial homeostasis in the nociceptive primary afferents. $\mathrm{C} 57 \mathrm{Bl} / 6$ mice submitted to the OXL-chronic neuropathy induction protocol by repeated intravenous administration of OXL $(1 \mathrm{mg} / \mathrm{kg})$ were evaluated to determine the paw mechanical and thermal nociceptive thresholds using the von Frey filaments and cold plate tests, respectively. Two weeks after the neuropathy induction, mice were treated with bone marrow-derived MSC $\left(1 \times 10^{6}\right)$, vehicle, or gabapentin $(\mathrm{GBP}, 70 \mathrm{mg} / \mathrm{kg})$. Four weeks later, mitochondrial morphology, gene expression profile, and oxidative stress markers in the sciatic nerve and dorsal root ganglia (DRG) were evaluated by transmission electron microscopy, RT-qPCR, and biochemical assays, respectively. OXL-treated mice presented behavioral signs of sensory neuropathy, such as mechanical allodynia and thermal hyperalgesia. The behavioral painful neuropathy was completely reverted by a single administration of MSC, while the daily treatment with GBP induced only a short-lived antinociceptive effect. The ultrastructural analysis of the sciatic nerve and DRG of OIPN mice revealed a high proportion of atypical mitochondria in both myelinated and unmyelinated fibers. Importantly, this mitochondrial atypia was strongly reduced in MSC-treated neuropathic mice. Moreover, MSC-treated neuropathic mice showed upregulation of Sod and Nrf2 mRNA in the sciatic nerve and DRG. In line with this result, MSC reduced markers of nitrosative stress and lipid peroxidation in the sciatic nerve and DRG from OIPN mice. Our data suggest that the reestablishment of redox homeostasis in the nociceptive primary afferents is a mechanism by which MSC transplantation reverts the OXL-induced chronic painful neuropathy.
\end{abstract}




\section{Introduction}

Sensory peripheral neuropathy is a common side effect seen in cancer patients treated with the chemotherapeutic agent oxaliplatin (OXL), and one of the main reasons for withdrawal of this antitumor therapy. OXL is a third-generation platinum analogue widely used for treatment of metastatic colon cancer, alone or in combination with other agents [1]. Structurally similar to cisplatin, OXL presents structural modifications that increases its antitumor activity and reduces its nephrotoxicity. On the other hand, OXL has a greater potential for neurotoxicity than other platinum compounds [2]. Approximately 20$50 \%$ of OXL-treated colorectal cancer patients develop peripheral neuropathy that persists for months to years after the end of chemotherapy [3]. Clinically, the symptoms of oxaliplatininduced peripheral neuropathy (OIPN) include reduced pain threshold, paresthesia, and dysesthesia, affecting lower and upper extremities in a characteristic distribution of "glove and stocking" $[3,4]$. Some clinical features are represented in animal models, which present a neuropathic syndrome induced by OXL also characterized by aberrant somatosensory processing and pain-like behaviors $[5,6]$.

Platinum concentrations in peripheral nervous tissue are similar to that found in the tumor tissue, and comparatively, much lower concentrations are found in the brain $[7,8]$. At the cellular level, following intracellular hydrolysis, OXL accumulates in the neurons and forms platinum-DNA (PtDNA) adducts with both nuclear and mitochondrial DNA, resulting in DNA damage and inhibition of DNA replication and transcription, leading to the production of free radicals and neuronal apoptosis $[9,10]$.

The pathophysiological mechanisms of OIPN converge to three of the most extensively studied pathways: oxidative stress, inflammation, and apoptosis. Among them, oxidative stress associated with mitochondrial dysfunction in the sensory peripheral nerve has emerged as a central mechanism for induction and maintenance of the OIPN [11-14]. The mitotoxicity hypothesis considers that Pt-DNA adducts induce mitochondrial damage associated with depletion of energy production in nociceptive primary afferent neurons, resulting in axonal degeneration and abnormal spontaneous discharges. The accumulation of Pt-DNA adducts alters the expression pattern of mitochondrial matrix proteins and transmembranic and mitochondrial intermembranes, important for the oxidative phosphorylation activities. The phosphorylative machinery, which is also the primary locus of the peroxynitrite formation and reactions, presents the potential of the mitochondrial membrane to disintegrate due to the nitration of proteins. Consequently, disruption of phosphorylative activity exacerbates mitochondrial damage, which causes neuronal energy deficit $[12,15]$. In fact, functional deficits in peripheral nerve mitochondria have been associated with the oxaliplatin-evoked painful neuropathy [16]. Oxidative stress induced by OXL can also cause mitochondrial dysfunction in neurons of the dorsal root ganglia (DRG), leading to cellular energy failure in nociceptive neurons [15].

One of the main problems concerning OIPN is related to its poor response to the currently available analgesic therapy. Clinical management of chemotherapy-induced neuropathic pain mainly includes gabapentinoids, such as gabapentin and pregabaline, and antidepressants, such as amitriptyline and duloxetine. However, despite being the first-line drugs for controlling neuropathic pain, their use is largely limited due to poor efficacy or undesirable side effects [4]. Moreover, none of these drugs has been shown to reverse cellular damage established after OXL cycles and restore organelle homeostasis in sensory neurons during chronic neuropathic states $[4,17]$. Based on the role of mitochondrial damage to the OIPN development, pharmacological studies have investigated possible therapeutic effects of mitoprotective agents to prevent or relieve OXL-evoked pain. These include several antioxidant compounds, such as n-acetylcysteine, n-acetyl carnitine, glutathione, alpha-lipoic acid, and vitamin E, which, however, have shown limited efficacy due to failure in modifying redox signaling pathways [18].

Due to this gap in the pharmacological treatment, cell therapy with mesenchymal stem/stromal cells (MSC) has been investigated and considered a promising therapeutic approach for the treatment of sensory neuropathies. The strategy of mesenchymal cell transplantation for the treatment of chronic neuropathies is based on cell-induced analgesia and its potential for nervous system repair, which has been attributed to the neuroprotective, neuroregenerative, or immunomodulatory properties of these cells [19-21]. The therapeutic effect of bone marrow-derived MSC has been demonstrated in different types of experimental sensory neuropathies, such as diabetic neuropathy [22-24], traumatic nerve injury [25-27], spinal cord injury [28], and chemotherapy-induced neuropathy [19, 29-31].

MSC have an important antioxidant action, being capable of protecting tissues from the harmful effects of ROS [32-34], which may represent a therapeutic advantage for OIPN treatment. MSC induce the expression of antioxidant enzymes which constitute a crucial cellular protection system against oxidative stress $[23,35]$. Additionally, the therapeutic potential of MSC in oxidative damage has also been attributed to mitochondrial transfer capacity between MSC and damaged tissue, leading to restoration of mitochondrial respiratory function [36-40]. The effects of MSC on cellular redox homeostasis may be due to the transference of soluble factors, which are also related to analgesia and neuroprotection [41-43], as well as mitochondrial donation [36]. These relevant properties of MSC confer an outstanding potential for repairing tissues that have undergone metabolic alterations and oxidative dysregulation, such as those observed during OIPN.

Considering this scenario, the present study was designed to evaluate the hypothesis that MSC transplantation reverts the oxaliplatin-induced sensory neuropathy via reducing oxidative stress and mitochondrial dysfunction in the nociceptive primary afferents.

\section{Materials and Methods}

2.1. Animals. Experiments were performed on male $\mathrm{C} 57 \mathrm{Bl} / 6$ mice (20-23 g) obtained from the Animal Facilities of Instituto Gonçalo Moniz/FIOCRUZ (Brazil). Mice were housed under a 12:12 h dark-light cycle. Animals had access to water 
and food ad libitum and were housed in temperaturecontrolled rooms $\left(22-25^{\circ} \mathrm{C}\right)$. All behavioral tests were performed between 8:00 a.m. and 5:00 p.m., and animals were only tested once. Animal care and handling procedures were in accordance with the National Institutes of Health guide for the care and use of laboratory animals $(\mathrm{NIH}, 8023)$ and the Institutional Animal Care and Use Committee FIOCRUZ (CPqGM 025/2011). Every effort was made to minimize the number of animals used and to avoid any unnecessary discomfort.

2.2. Production of Mesenchymal Stem/Stromal Cells (MSC). MSC were obtained from the bone marrow of femurs and tibiae of male $\mathrm{C} 57 \mathrm{Bl} / 6$ mice, following the methods described by Soleimani and Nadri [44]. A population of MSC with spindle-shaped morphology was maintained at $37^{\circ} \mathrm{C}$ with $5 \% \mathrm{CO}_{2}$ and expanded during 5-6 passages in DMEM medium supplemented with $2 \mathrm{mM}$ L-glutamine, $1 \mathrm{mM}$ sodium pyruvate, $50 \mu \mathrm{g} / \mathrm{mL}$ gentamycin, and $10 \%$ fetal bovine serum (all reagents were acquired from Sigma). When $80-90 \%$ confluence was reached, cells were detached using $0.25 \%$ trypsin (Invitrogen Molecular Probes, Eugene, OR, USA). Cells were then washed with serum-free medium and resuspended in $0.9 \%$ saline solution. Finally, cell suspensions were counted using a hemacytometer and transplanted into mice via tail vein injection $\left(1 \times 10^{6}\right.$ cells/mouse in a final volume of $100 \mu \mathrm{L}$ of sterile saline solution with $10 \%$ heparin).

The identity of MSC was confirmed on the basis of morphological criteria, plastic adherence, and specific surface antigen expression evaluated by flow cytometry. The analysis of cell surface markers showed that MSC expressed low levels of hematopoietic cell lineage markers (0.7\% CD45, 1.3\% CD34, and 1.6\% CD11b) and expressed common MSCspecific cell surface markers such as CD90 (90\%), CD44 (99\%), CD73 (83\%), and Sca-1 (88\%). Additionally, the differentiation capacity into osteocytes, adipocytes, and chondrocytes was evaluated after induction using specific media, as previously described [23]. MSC differentiations were confirmed by the presence of mineralizing cells after staining with alizarin red (osteocytes), lipid droplets after staining with oil red (adipocytes), or glycosaminoglycans after staining with Alcian blue (chondrocytes).

2.3. OXL-Induced Peripheral Neuropathy Model. Following the methods employed by Azevedo et al. [45], the chronic peripheral neuropathy model in mice was established by intravenous administration of OXL $(1 \mathrm{mg} / \mathrm{kg})$, twice a week in alternating days, for 4.5 weeks, totaling 9 administrations. A stock solution of OXL was prepared in distilled water $(1 \mathrm{mg} / \mathrm{mL})$. At the time of administration, the stock solution was diluted in 5\% dextrose solution (final concentration $0.1 \mathrm{mg} / \mathrm{mL}$ ). After baseline assessments of motor performance, body weight, and nociceptive thresholds, the animals started the induction cycle by repeated injection of OXL through the lateral vein of the tail. The control group mice received nine intravenous injections of vehicle (5\% dextrose) instead of OXL. The OXL-induced chronic painful neuropathy development was evidenced by the reduction of the nociceptive thresholds.
2.4. Mechanical and Thermal Nociceptive Threshold Evaluation. Sensory parameters of OIPN were assessed throughout the experimental period by using the established behavioral assays that evaluate mechanical and thermal nociceptive thresholds [46, 47], as described by Evangelista et al. [23], and the method description partly reproduces their wording. Withdrawal threshold to mechanical stimulation was measured using von Frey filaments (Stoelting; Chicago, IL, USA). In a quiet room, mice were placed in acrylic cages $(12 \times 10 \times 17 \mathrm{~cm})$ with a wire grid floor, which allowed full access to the ventral aspect of the hind paws, $40 \mathrm{~min}$ before the beginning of the test. A series of 9 filaments $(0.04-4 \mathrm{~g})$ was applied to the plantar surface of the ipsilateral hind paw to determine the threshold stiffness required for 50\% paw withdrawal, according to the nonparametric method of Dixon, as described by Chaplan et al. [46, 48]. A positive response was characterized by the removal of the paw followed by clear flinching movements. The development of OIPN was characterized by mechanical allodynia, indicated by the reduction of the paw withdrawal threshold (in grams).

Withdrawal threshold to cold stimulation was determined using the cold plate test, following the methods described by $\mathrm{Ta}$ et al. [47]. Mice underwent an acclimatization period before the beginning of the test. The mice were placed on a smooth surface at controlled temperature at $-2.5^{\circ} \mathrm{C}$, remaining for 5 minutes under observation. Total nociceptive behaviors, such as licking, shaking, and raising the hind paw, were recorded. The increase in nociceptive behavior indicates the development of cold thermal hyperalgesia, which is considered a hallmark of the OIPN.

2.5. Motor Function Assay. Since the behaviors evaluated in nociceptive tests depend on the integrity of the motor capacity of the mice, the motor performance was monitored throughout the experimental period using the rotarod test. We followed the methods of Santos et al. [49], and the method description partly reproduces their wording. The rotarod apparatus (Insight, Ribeirão Preto, Brazil) consisted of a bar with a diameter of $3 \mathrm{~cm}$, subdivided into five compartments. The bar rotated at a constant speed of 8 revolutions per min. The animals were selected $24 \mathrm{~h}$ previously by eliminating those mice that did not remain on the bar for two consecutive periods of $120 \mathrm{~s}$. On the test day, mice from different experimental groups were placed on a rotating rod, and the resistance to falling was measured up to $120 \mathrm{~s}$. Mice treated with diazepam $(10 \mathrm{mg} / \mathrm{kg}$; Cristália, Itapira, Brazil), the reference drug of the test, were placed on a rotating rod one hour after treatment. The results are expressed as the average time (s) the animals remained on the rotarod in each group.

2.6. Experimental Design. Mice were divided into the following experimental groups $(n=6)$ : nonneuropathic mice (received nine intravenous injections of 5\% dextrose instead of OXL; control group), neuropathic mice plus vehicle of MSC treatment (OXL+saline), and neuropathic mice plus MSC treatment (OXL+MSC). For the behavioral assays, we also included a gold standard analgesic group and control: neuropathic mice plus vehicle of GBP treatment (OXL 
+saline) and neuropathic mice plus GBP (OXL+GBP, reference drug). Mechanical and thermal nociceptive thresholds were evaluated at baseline and daily after OIPN induction in all groups. Two weeks following the model induction, and after the establishment of the painful neuropathy evidenced by nociceptive threshold reduction, mice received a single administration of MSC $1 \times 10^{6} \mathrm{MSC} /$ mouse in a final volume of $100 \mu \mathrm{L}$ via tail vein, or saline $(100 \mu \mathrm{L})$, following the methods described by Evangelista et al. [23]. The number of transplanted MSC was defined based on previous works $[23,26]$. The effect of GBP, considered the gold standard in the clinical control of sensory neuropathies, was investigated here in order to validate the predictive capacity of the chronic sensory neuropathy model used and to evidence the magnitude of the MSC-induced antinociceptive effect. To this end, two weeks following the model induction, neuropathic mice received oral administrations of GBP $(70 \mathrm{mg} / \mathrm{kg}$; $12 / 12 \mathrm{~h}$ ) or vehicle (saline $12 / 12 \mathrm{~h}$ ) for six consecutive days. During the 6 days of GBP treatment, nociceptive thresholds were daily assessed in two moments, immediately before and one hour after the first dose of the day, and then, daily until the end of the experimental period. The dose and frequency of GBP administration used here were defined based on a previous work [50]. Nociceptive behavioral tests were performed during the 10-week experimental period, both in MSC-treated and GBP-treated mice. In all experimental groups, motor performance and body weight were recorded weekly.

\subsection{Morphological and Morphometric Analysis of} Mitochondria in Primary Afferent Neurons. Four weeks after MSC transplantation, mice were euthanized and sciatic nerve samples $( \pm 1 \mathrm{~cm})$ and DRG (L4-L5) were collected, processed, and subjected to morphological and morphometric analyses by transmission electron microscopy, following the methods described by Evangelista et al. [23]. The samples were fixed in $2.5 \%$ glutaraldehyde (grade I, Sigma) in $0.1 \mathrm{M}$ sodium cacodylate buffer overnight; washed in cacodylate buffer; postfixed in $1 \%$ osmium tetroxide (Sigma), $0.8 \%$ potassium ferricyanide, and $5 \mathrm{mM} \mathrm{CaCl} 2$ in the same buffer for $60 \mathrm{~min}$; serially dehydrated using graded acetone; and embedded in Poly/Bed resin (Polysciences, Warrington, PA, USA). For ultrastructural analysis of mitochondria in sensory fibers of the sciatic nerve and DRG neurons, ultrathin sections $(70 \mathrm{~nm})$ were stained with $5 \%$ uranyl acetate for $30 \mathrm{~min}$ and $15 \%$ lead citrate for $5 \mathrm{~min}$ and observed in JEOL electron microscope (JEM-1230). Morphological and morphometric evaluations of mitochondria in myelinated and unmyelinated neurons were performed, following the methods described by Flatters and Bennett [51]. Briefly, we counted 60 myelinated fibers and 60 unmyelinated fibers in each sample $(n=6)$ and quantified the total number of mitochondria in each fiber. Mitochondrial atypia was evidenced by increased organelle size (length greater than $265 \mathrm{~nm}$ ), formation of vacuoles greater than $50 \%$ of the mitochondrial area, and accumulation of electron-dense amorphous material on mitochondrial poles, in line with previously established criteria [51]. The level of mitochondrial atypia was represented as a percentage in relation to the total mitochon- drial count. Analyses were performed using the software Image-Pro Plus 7.01 (Media Cybernetics, Rockville, MD, USA).

2.8. Real-Time PCR. Four weeks after MSC transplantation, mice were euthanized and sciatic nerve samples $( \pm 1 \mathrm{~cm})$ and DRG (L4-L5) were collected and processed for the gene expression analysis by real-time quantitative polymerase chain reaction (qRT-PCR). The transcription of the antioxidant genes superoxide dismutase (Sod1) and nuclear factor2 erythroid related factor-2 (Nrf2) was evaluated as described by Santos et al. [52]. RNA was extracted of the sciatic nerve and DRG samples using TRIzol reagent (Invitrogen Molecular Probes, Eugene, OR, USA), and the RNA concentration was determined by photometric measurement (NanoDrop 2000c Spectrophotometer; Thermo Fisher Scientific, Waltham, MA, USA). A High-Capacity cDNA Reverse Transcription Kit (Applied Biosystems, Foster City, CA, USA) was used to synthesize cDNA from $1 \mu \mathrm{g}$ of RNA, according to the manufacturer's recommendations. The qPCR was prepared with TaqMan ${ }^{\circledR}$ Universal PCR Master Mix (Applied Biosystems). qRT-PCR assays were performed to detect the expression levels of Sod1 (Assay ID Mm01344233_g1) and Nrf2 (Assay ID Mm00477784_m1) (Thermo Fisher Scientific). All reactions were run in triplicate on an ABI 7500 Real-Time PCR System (Applied Biosystems) under standard thermal cycling conditions. A nontemplate control (NTC) and nonreverse transcription controls (No-RT) were also included. The samples were normalized with Gapdh (Assay ID Mm99999915_g1). The threshold cycle (2- $\Delta \Delta \mathrm{Ct}$ ) method of comparative PCR was used to analyse the data, as described by Schmittgen and Livak [53].

2.9. Estimation of Nitrite and Lipid Peroxidation. To determine the levels of nitrite and lipid peroxidation, we followed the methods described by Evangelista et al. [23], and the description of the methods partially reproduces their wording. Four weeks after MSC transplantation, samples of sciatic nerve $( \pm 1 \mathrm{~cm})$ and DRG (L4-L5) were collected bilaterally, rinsed with ice-cold saline and homogenized in chilled phosphate buffer ( $\mathrm{pH}$ 7.4). The malondialdehyde (MDA) content, a marker of lipid peroxidation, was assayed in the form of thiobarbituric acid-reactive substances, as previously described by Tiwari et al. [54]. Briefly, $0.5 \mathrm{~mL}$ of homogenate and $0.5 \mathrm{~mL}$ of Tris- $\mathrm{HCl}$ were incubated at $37^{\circ} \mathrm{C}$ for $2 \mathrm{~h}$. After incubation, $1 \mathrm{~mL}$ of $10 \%$ trichloroacetic acid was added, and the sample was centrifuged at $1000 \mathrm{~g}$ for $10 \mathrm{~min}$. To $1 \mathrm{~mL}$ of supernatant, $1 \mathrm{~mL}$ of $0.67 \%$ thiobarbituric acid was added, and the tubes were kept in boiling water for $10 \mathrm{~min}$. After cooling, $1 \mathrm{~mL}$ of double distilled water was added, and the absorbance was measured at $532 \mathrm{~nm}$. The total protein concentration of the samples was estimated using the Bradford protein assay, and the malondialdehyde content was expressed as micromoles of malondialdehyde per milligram of protein $(\mu \mathrm{mol} / \mathrm{mg})$. Nitrite was estimated in the sciatic nerve and DRG homogenate using the Griess reagent and was used as an indicator of nitric oxide production [55]. Briefly, $500 \mu \mathrm{L}$ of Griess reagent (1:1 solution of $1 \%$ sulfanilamide in $5 \%$ phosphoric acid and $0.1 \%$ naphthylamine 
diamine dihydrochloric acid in water) was added to $100 \mu \mathrm{L}$ of homogenate. Absorbance was measured at $546 \mathrm{~nm}$, and the nitrite concentration, expressed as micrograms of nitrite per milligram of protein $(\mu \mathrm{g} / \mathrm{mg})$, was calculated using a standard curve of sodium nitrite.

2.10. Statistical Analyses. All data are presented as means \pm SD of measurements made on six animals in each group. For repeated measures (nociceptive threshold data), comparisons between groups were made by two-way ANOVA with Bonferroni's post hoc test. The factors analysed were treatments, time, and treatment-time interaction. Remaining data were analysed using one-way ANOVA followed by Tukey's posttest. For morphometric analysis, Shapiro-Wilk test was performed, and because all data were positive for normality, one-way ANOVA was used. All data were analysed using the GraphPad Prism v.5.0 software (GraphPad, San Diego, CA, USA). Differences were considered statistically significant for $p$ values $<0.05$.

\section{Results}

3.1. MSC Transplantation Reverts Long-Term Sensory Dysfunctions in Mice with OIPN. In the OIPN model, behavioral assessment showed that MSC-treated neuropathic mice have nociceptive thresholds increased for mechanical and thermal stimuli, while GBP induced just transient effects in neuropathic mice. Behavioral signs of painful neuropathy, characterized by the reduction of nociceptive thresholds, were evident starting from the second week of the OXL administration cycle. After the model induction, mechanical allodynia (Figure 1(a)) and cold thermal hyperalgesia (Figure 1(c)) persisted throughout the experimental period (10 weeks; $p<0.001$ ). To verify whether MSC were able to revert the established painful neuropathy, mice were treated with MSC $\left(1 \times 10^{6}, 100 \mu \mathrm{L}\right)$ or vehicle $(100 \mu \mathrm{L})$, 2 weeks after OIPN induction. One week after transplantation, MSCtreated neuropathic mice exhibited reduction of the behavioral painful neuropathy compared to vehicle-treated neuropathic mice $(p<0.001)$. The antinociceptive effect of MSC was progressive, achieving a complete reversal of mechanical allodynia (Figure $1(\mathrm{a}) ; p<0.001$ ) and thermal hyperalgesia (Figure $1(\mathrm{c}) ; p<0.001$ ) in 2 and 1 weeks after treatment, respectively. Over the second week, a group of mice was daily treated with the gold standard drug GBP $(70 \mathrm{mg} / \mathrm{kg}, 12 / 12 \mathrm{~h}$, p.o.), whereas a control group received saline solution (p.o.). GBP-treated neuropathic mice exhibited a transient antinociceptive effect (Figures 1(b) and 1(d), $p<0.05$ ) during the treatment period. There were no signs of motor impairment in mice from the different experimental groups, as assessed by the rotarod test (data not shown).

3.2. MSC Treatment Reduces the Frequency of Mitochondrial Atypia in Primary Afferent Neuron Fibers of the Sciatic Nerve of OIPN Mice. Since OIPN is associated with mitochondrial alterations in the peripheral nervous system, morphologic and morphometric analyses of mitochondria present in myelinated and unmyelinated fibers of the sciatic nerve were evaluated by transmission electron microscopy. Based on preestablished parameters of mitochondrial atypia, such as size, vacuoles, and swelling, electron photomicrographs of the sciatic nerves of nonneuropathic mice showed a low occurrence of atypical mitochondria in axons of myelinated fibers (Figure 2(a)) and unmyelinated fibers (Figure 2(d)). Mice with OXL-induced chronic neuropathy showed an increased incidence of vacuolated and swollen mitochondria in peripheral nociceptive neurons (Figures 2(b) and 2(e)) compared to control nonneuropathic mice. Morphometric data showed that $54.4 \%$ of mitochondria in myelinated fibers (Figure $2(\mathrm{~g})$ ) and $39.3 \%$ of mitochondria in unmyelinated fibers (Figure 2(h)) were atypical in vehicle-treated neuropathic mice. In nonneuropathic mice, 17.6 and $8.9 \%$ of mitochondrial atypia were evidenced in myelinated and unmyelinated fibers, respectively. These data show a relevant increase in mitochondrial atypia in mice with OXL-induced neuropathy $(p<0.001)$. In contrast, MSC-treated neuropathic mice had a reduction $(p<0.001)$ in the proportion of atypical mitochondria in myelinated (Figure 2(c)) and unmyelinated fibers (Figure 2(f)).

Morphologic and morphometric analyses of the DRG (Figure 3) showed a similar profile of mitochondrial atypia to that observed in the sciatic nerve fibers. Neuropathic mice (Figures 3(B) and 3(E)) showed an increased percentage of atypical mitochondria compared to the control group (Figures 3(A) and 3(D); $p<0.001$ ). Electron microscopy data showed that nonneuropathic mice had $35.9 \%$ of DRG atypical mitochondria, whereas $79.5 \%$ were atypical in OXLneuropathic mice (Figure $3(\mathrm{G})$ ). MSC treatment was able to reduce $(p<0.001)$ the percentage of atypical mitochondria in neuropathic mice (Figures $3(\mathrm{C})$ and $3(\mathrm{~F})$ ).

3.3. Treatment with MSC Increased the Antioxidant Profile in the Peripheral Nervous System of Mice with OXL-Induced Chronic Neuropathy. Considering the mitochondrial data and the key role of oxidative stress in the pathophysiology of OIPN, the effect of MSC on the redox balance in the peripheral nervous system of neuropathic mice was next evaluated. Four weeks after transplantation, MSC-treated neuropathic mice presented increased expression of Sod and Nrf2 mRNA in the sciatic nerve (Figures 4(a) and 4(b), respectively) and DRG (Figures 4(c) and 4(d), respectively), when compared to vehicle-treated neuropathic mice $(p<0.01)$. Vehicle-treated neuropathic mice showed similar levels of Sod and Nrf2 mRNA compared to control mice.

\subsection{Effect of MSC Treatment on Oxidative Stress Markers in} the Peripheral Nervous System during OXL-Induced Chronic Neuropathy. The effects of the MSC transplantation on nitrosative stress and lipid peroxidation were evaluated by measuring the nervous tissue levels of nitrite and MDA four weeks after transplantation (Figure 5). MDA levels were enhanced in the sciatic nerve (Figure 5(a)) and DRG (Figure 5(c)) of neuropathic mice, compared to the levels found in control mice $(p<0.01)$. MSC transplantation reduced $(p<0.001)$ the levels of MDA in the sciatic nerve and DRG of neuropathic mice, which presented levels similar to those observed in nonneuropathic control mice. A similar profile effect was observed with nitrite levels, since the 


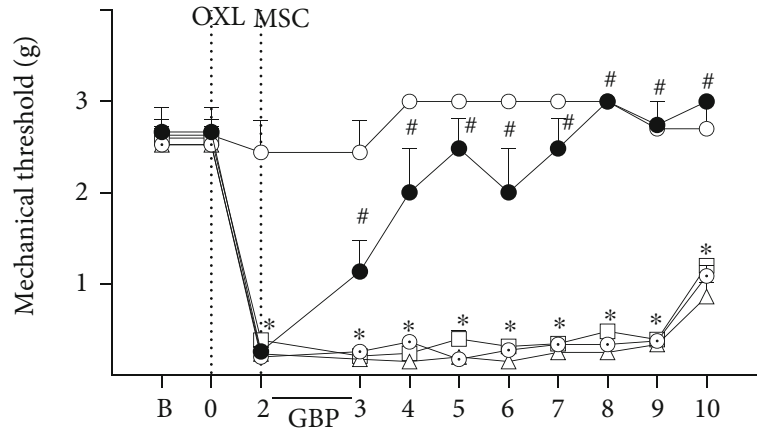

Weeks after OXL injection

(a)

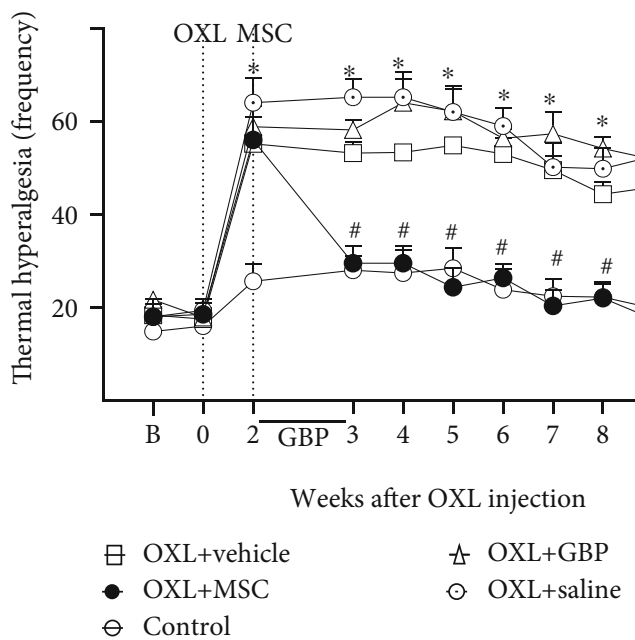

(c)

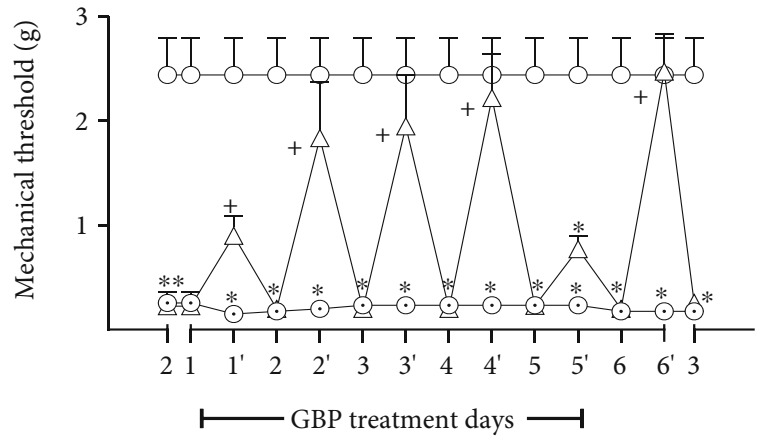

(b)

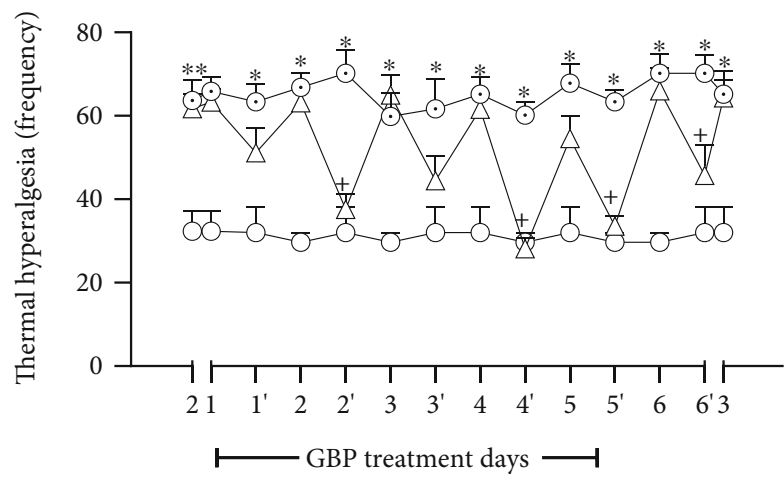

(d)

FIgURE 1: Pain-like behaviors of mice treated with MSC or gabapentin on the OXL-induced painful neuropathy model. (a, b) show mechanical nociceptive threshold data: the strength of the filament (grams) in which the animal responds in 50\% of the presentations ( $y$ -axis) in relation to time ( $x$-axis), given in weeks (a) or days (b), after induction of the neuropathy model. (c, d) show cold thermal hyperalgesia data: the frequency of nociceptive behaviors ( $y$-axis) in relation to time ( $x$-axis), given in weeks (c) and days (d), after OXL induction. The nociceptive threshold was evaluated in the mice before (b) and after OXL induction (week 0). The control group represents nonneuropathic mice that received vehicle (5\% dextrose) instead of OXL. Two weeks after the model induction, mice were intravenously treated with MSC (OXL+MSC; $\left.1 \times 10^{6} / 100 \mu \mathrm{L}\right)$ or vehicle $(\mathrm{OXL}+$ vehicle; $100 \mu \mathrm{L})$ or orally treated with gabapentin $(\mathrm{OXL}+\mathrm{GBP} ; 70 \mathrm{mg} / \mathrm{kg}$; 12/12 h; 6 consecutive days) or saline (OXL+saline; 12/12 h; 6 consecutive days). During the 6 days of GBP treatment, nociceptive thresholds were daily assessed in two moments: immediately before and one hour after the GBP administration. (b, d) show nociceptive threshold data before (time points 1, 2, 3, 4, 5, and 6) and after (time points $1^{\prime}, 2^{\prime}, 3^{\prime}, 4^{\prime}, 5^{\prime}$, and $6^{\prime}$ ) the administration of GBP. Data are expressed as means \pm standard deviation; $n=6$ mice per group. ${ }^{*}$ Statistical significance relative to the control group $(p<0.001) ;{ }^{*}$ statistical significance relative to the OXL+vehicle group $(p<0.001)$; ${ }^{+}$statistical significance relative to the OXL+saline group $(p<0.05)$, as determined by two-way ANOVA followed by Bonferroni posttest.

elevated levels found in the sciatic nerve (Figure 5(b)) and DRG (Figure $5(\mathrm{~d})$ ) of mice with OXL-induced sensory neuropathy $(p<0.01)$ were fully normalized by MSC transplantation $(p<0.001)$.

\section{Discussion}

The present study demonstrated that treatment with MSC reverts the sensory alterations associated with OXL-induced chronic peripheral neuropathy in mice, in parallel to the restoration of oxidative homeostasis and reduction of mitochondrial atypia in the nociceptive primary afferent. Therefore, this study points out a new mechanism possibly involved in the antinociceptive effect induced by MSC during neuropathic conditions and reinforces the therapeutic potential of these cells for the control of chronic painful neuropathies.

OXL-induced chronic peripheral neuropathy is characterized by increased excitability of nociceptive primary afferent neurons, leading to sensory disorders in patients, which persist even after discontinuity of chemotherapy cycles [14, 56, 57]. The neurotoxic effects of OXL lead to the development of dysesthesias and paresthesias of the hands and feet. These symptoms are often triggered by exposure to cold temperatures, which is a hallmark of OXL-induced painful neuropathy $[4,56]$. Cold hyperalgesia, characterized by 


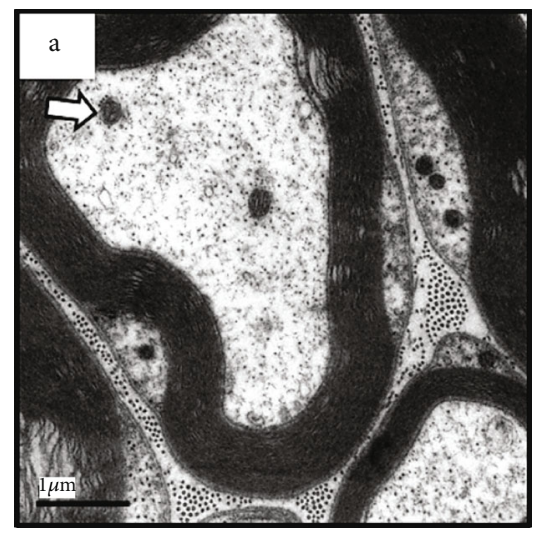

(a)

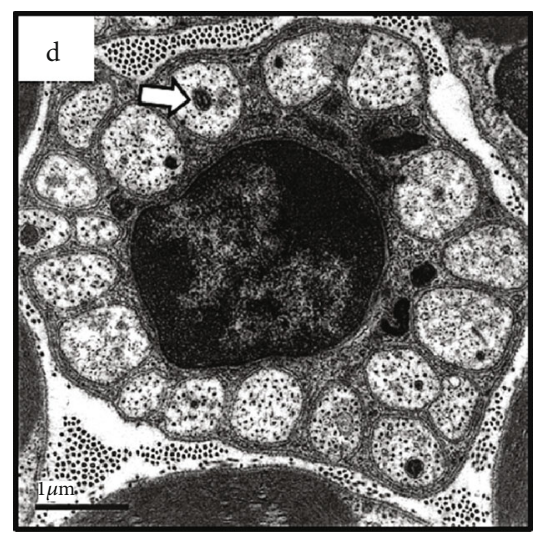

(d)

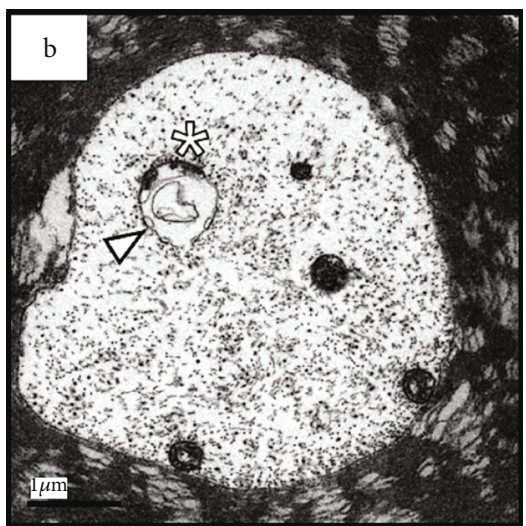

(b)

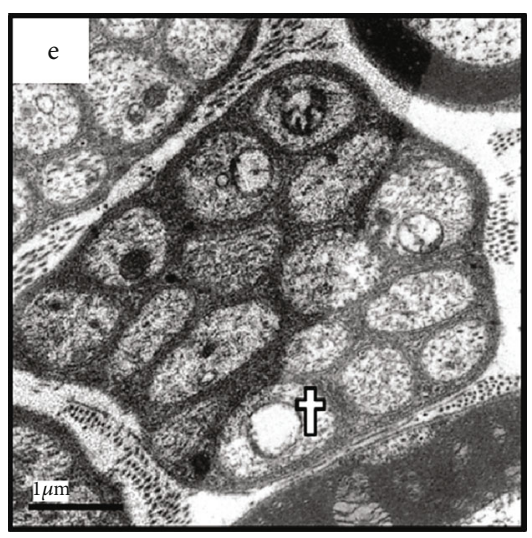

(e)

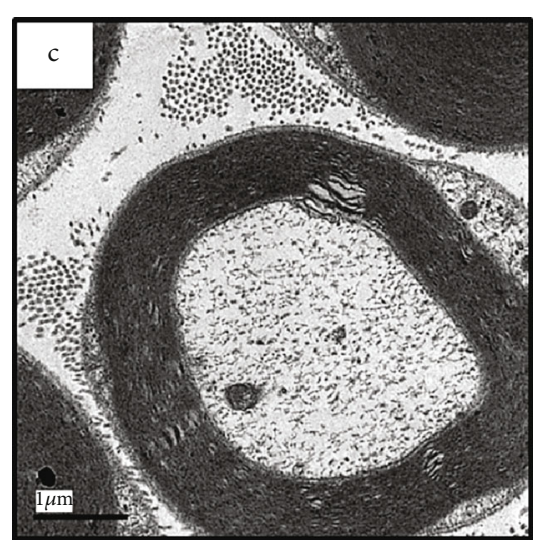

(c)

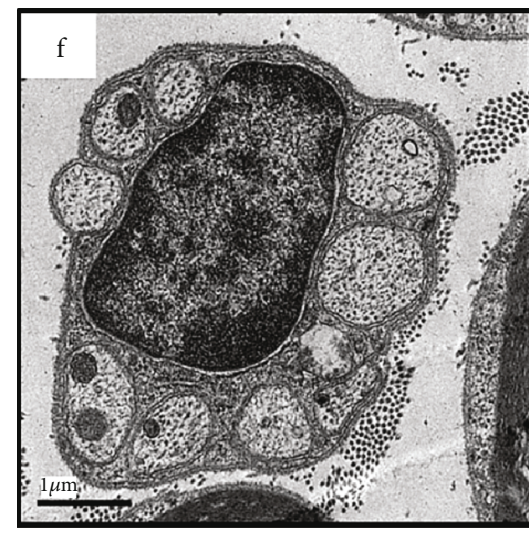

(f)

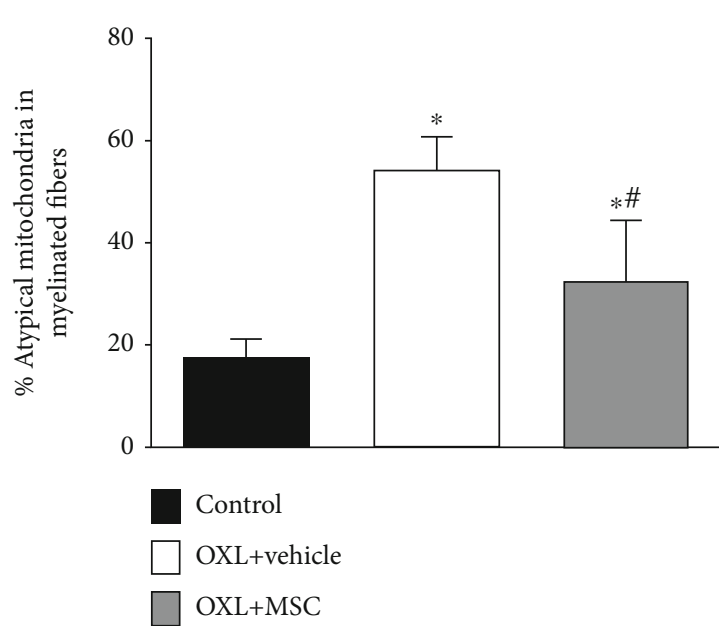

(g)

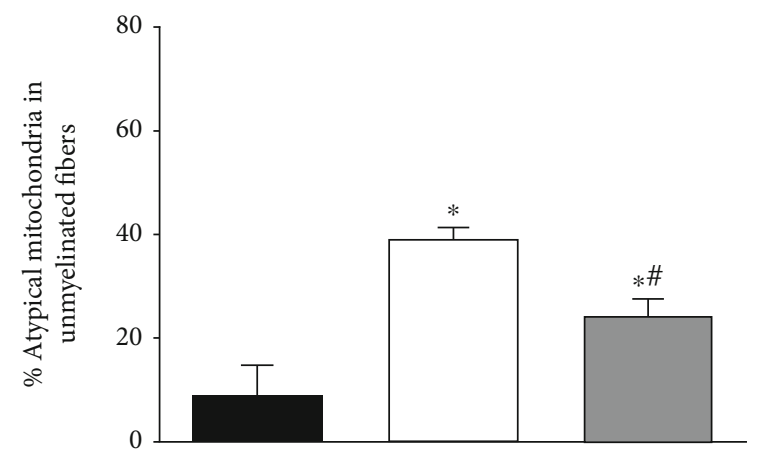

(h)

FIGURE 2: Effect of MSC on mitochondrial morphology and morphometry on sciatic nerve sensory fibers of mice with OXL-induced chronic neuropathy. Transmission electron micrographs of sciatic nerve cross-sections from nonneuropathic mice (control group) and neuropathic mice treated with vehicle (OXL+vehicle) or with $1 \times 10^{6}$ MSC (OXL+MSC). Panels show myelinated (a-c) and unmyelinated (d-f) fibers of the sciatic nerve. Analyses were performed 4 weeks after treatments. Electron micrograph of the control group reveals mitochondria with double intact membrane and absence of vacuolated intramitochondrial spaces and organelles with normal proportion area (arrow) in both myelinated (a) and unmyelinated fibers (d). Vehicle-treated neuropathic mice presented atypical mitochondria, characterized by increased organelle size (arrowhead), presence of vacuole greater than $50 \%$ of the mitochondrial area (asterisk), and accumulation of electron-dense amorphous material at the mitochondrial pole (cross), in both myelinated (b) and unmyelinated (e) fibers. MSC-treated neuropathic mice presented fewer mitochondrial morphological alterations in sensory fibers relative to vehicle-treated neuropathic mice (c, f). (g, h) show the percentage of atypical mitochondria found in myelinated and unmyelinated fibers, respectively. Scale bar $=1 \mu \mathrm{m}$. Data are expressed as means \pm standard deviation; $n=6$ mice per group. * Statistical significance relative to the control group $(p<0.001) ;{ }^{*}$ statistical significance relative to the OXL+vehicle group $(p<0.05)$, as determined by one-way ANOVA followed by Tukey's multiple comparison test. 


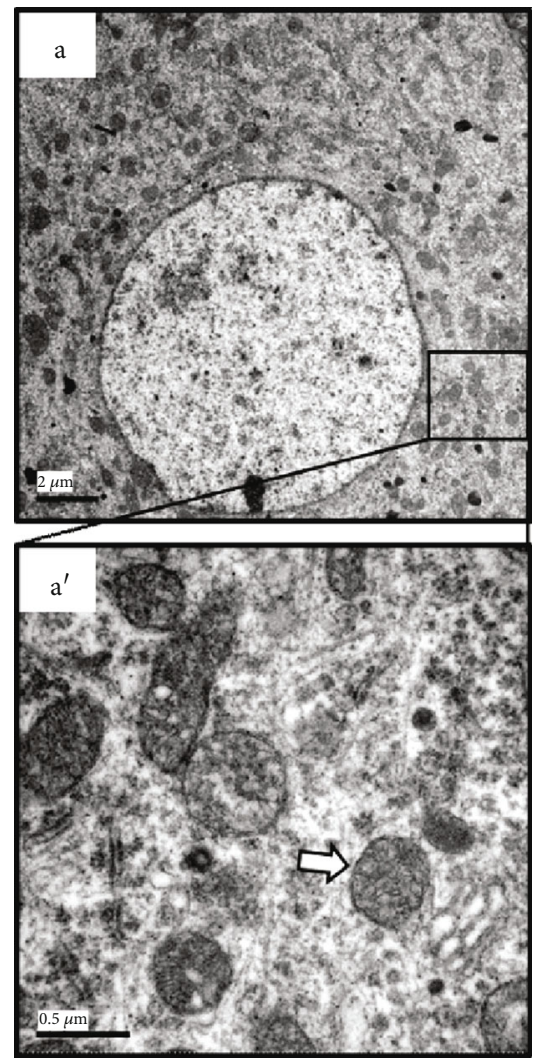

(a)

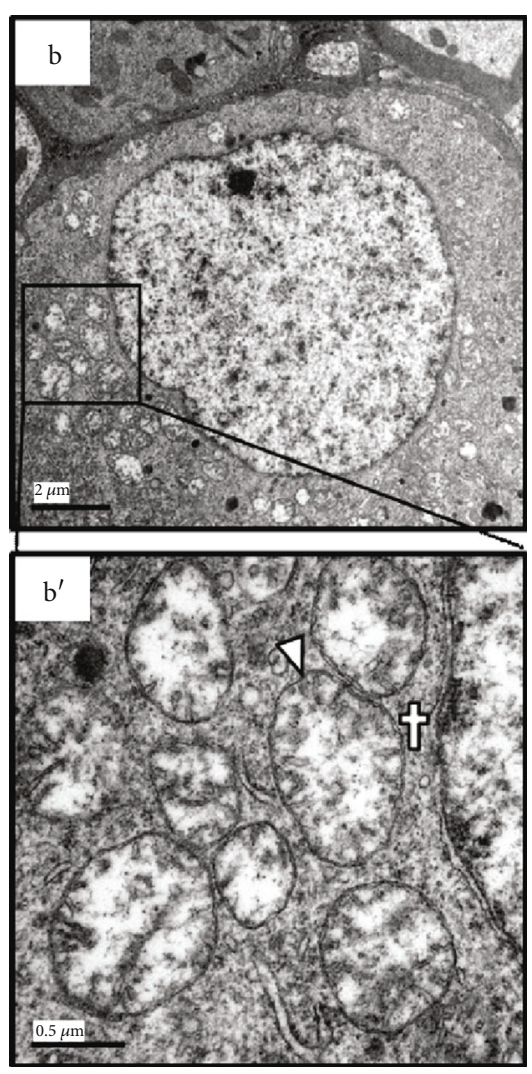

(b)

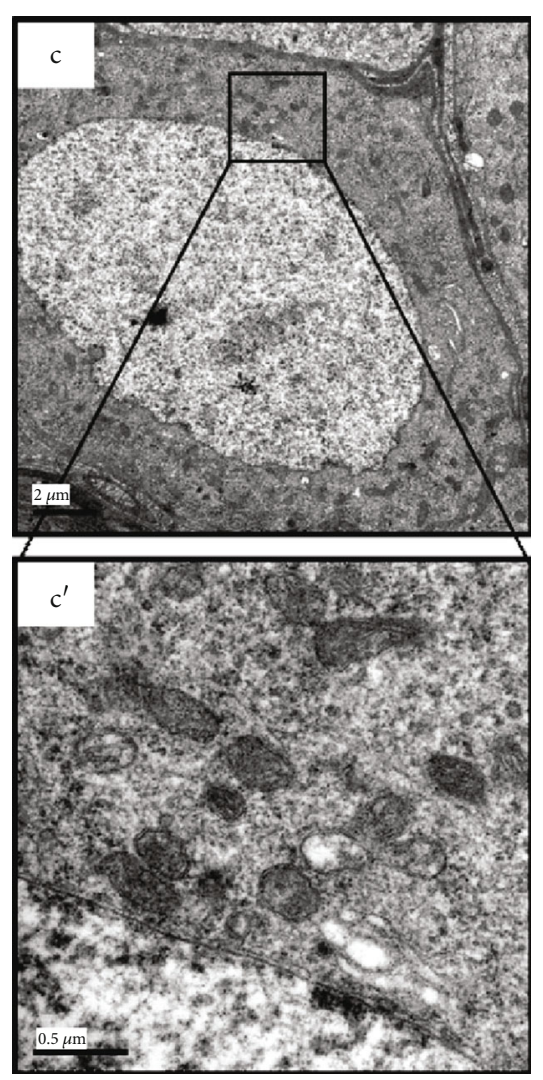

(c)

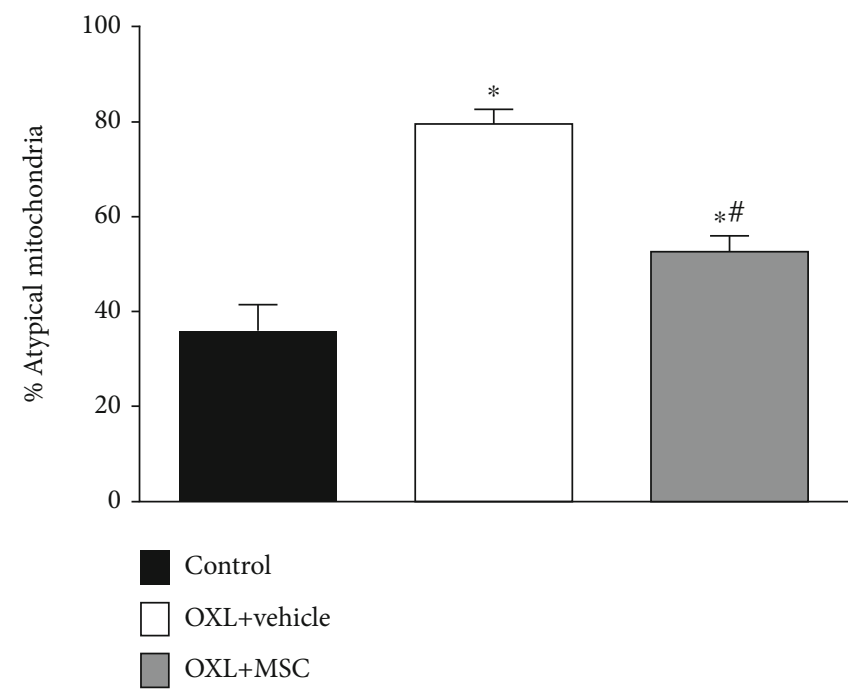

(d)

FIGURE 3: Effect of MSC on mitochondrial morphology and morphometry of dorsal root ganglia neurons of mice with OXL-induced chronic neuropathy. Electron micrographs representing dorsal root ganglia (DRG) cross-sections from nonneuropathic mice (A, D) (control group) and neuropathic mice treated with vehicle (B, E) (OXL+vehicle) or with $1 \times 10^{6} \mathrm{MSC}(\mathrm{C}, \mathrm{F})(\mathrm{OXL}+\mathrm{MSC})$. Analyses were performed 4 weeks after treatments. (A) Electron micrograph of the control group with numerous typical mitochondria. (D) Higher magnification (50,000x) of the highlighted area in (A), showing typical mitochondria, with intact membrane and mitochondria cristae (arrow). (B) Neuropathic mice treated with vehicle presented numerous atypical mitochondria. (E) Higher magnification image showing atypical mitochondria, characterized by increased organelle area (arrowhead) and accumulation of electron-dense amorphous material on mitochondrial poles (cross). MSC-treated neuropathic mice (C, F) presented fewer mitochondrial atypia relative to vehicle-treated neuropathic mice. Scale bar $=2 \mu \mathrm{m}$ (A-C) (10,000x magnification) and $0.5 \mu \mathrm{m}$ (D-F) (50,000x magnification). (G) shows the percentage of atypical mitochondria found in DRG. Data are expressed as means \pm standard deviation; $n=6$ mice per group. ${ }^{*}$ Statistical significance relative to the control group $(p<0.001)$; " statistical significance relative to the OXL+vehicle group $(p<0.05)$, as determined by one-way ANOVA followed by Tukey's multiple comparison test. 


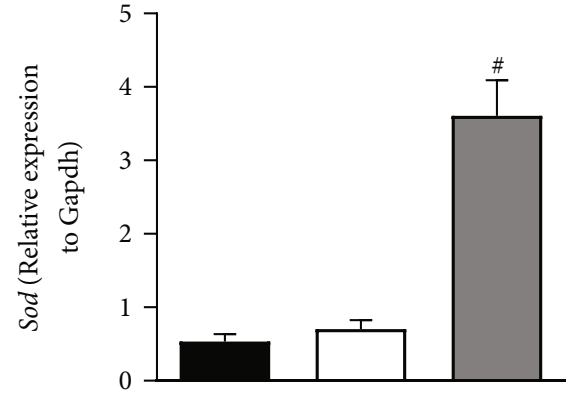

(a)

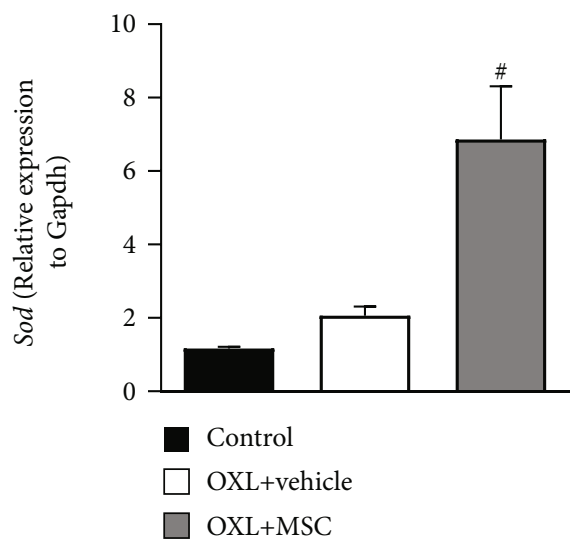

(c)

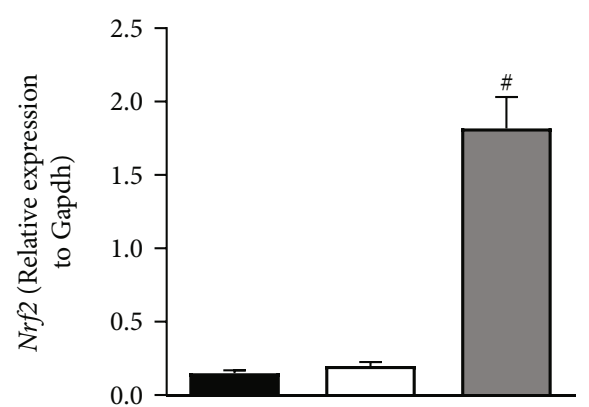

(b)

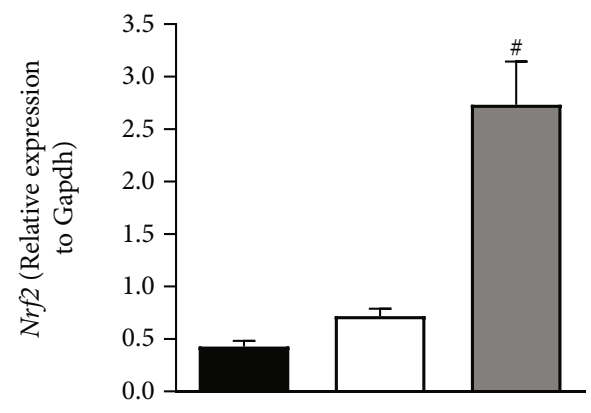

(d)

FIgURE 4: Effect of MSC on the expression of the antioxidant factors, Sod and Nrf2, in the sciatic nerve and dorsal root ganglia of mice with OXL-induced chronic neuropathy. Two weeks after the OIPN model induction, mice were treated with $1 \times 10^{6} \mathrm{MSC}(\mathrm{OXL}+\mathrm{MSC})$ or vehicle $(\mathrm{OXL}+$ saline) by endovenous route. Control group received 5\% dextrose instead of OXL. The levels of mRNA in the sciatic nerve (a, b) and DRG (c, d) were measured by RT-qPCR 4 weeks after treatment. Target gene expression is represented normalized by the internal control

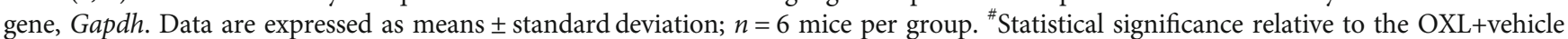
group $(p<0.01)$, as determined by one-way ANOVA followed by Tukey's multiple comparison test.

increased response to a cold painful stimulus, and mechanical allodynia, which is the induction of pain by innocuous stimuli, are frequent sensory symptoms found in patients with OXL-induced neuropathy [56]. Therefore, the sensory manifestation development by OIPN mice was compatible with the classic symptoms manifested by patients with OXL-induced neuropathy, suggesting a good clinical equivalence of the experimental model used in the present study. In addition, it is well described that chemotherapy-induced peripheral neuropathy predominantly affects sensory nerves [58], while the involvement of motor or autonomic nerves is rare [59]. In fact, we showed that chronic treatment of mice with OXL induced persistent changes in nociceptive sensitivity without affecting the motor function, as evidenced by the rotarod test.

MSC transplantation completely reverted the behavioral signs of OXL-induced painful neuropathy, an effect which persisted until the end of the experimental period. In fact, the antinociceptive effect of MSC has been demonstrated in different conditions of sensory neuropathy, both in experimental [60] and clinical [61] conditions. Corroborating the present data, the antinociceptive effect of MSC on oxaliplatin-induced neuropathy has recently been described $[30,62]$. Importantly, the long-lasting antinociception of MSC seen in the present study differed drastically from the antinociceptive effect induced by repeated gabapentin administration, which only induced antinociception in the first hours after administration. This long-lasting antinociceptive profile suggests that MSC modulate pathophysiological events of OIPN maintenance, rather than exerting an intrinsic analgesic action. Therefore, a key mechanism of the OIPN, which is the redox imbalance in the peripheral nervous system, was investigated here.

Considering that oxaliplatin causes mitochondrial dysfunction in sensory neurons [63], morphological and morphometric aspects of mitochondria were evaluated. Corroborating the study of Xiao and Bennett [64], transmission electron microscopy analysis showed a high percentage of atypical mitochondria in the primary sensory neurons of mice with OIPN. The correlation between mitochondrial changes and platinum compound-induced sensory neuropathy is already well established. Platinum products when binding to mitochondrial DNA form pt-DNA adducts, which cannot be repaired due to the absence of DNA repair systems in the mitochondria. Such pt-DNA adducts block DNA replication and mRNA transcription impairing mitochondrial integrity and favoring disarrangements in phosphorylative activity [65] in sensory neurons. Thus, the platinum compound family interferes with the synthesis of mitochondrial proteins that can generate several abnormalities to this 


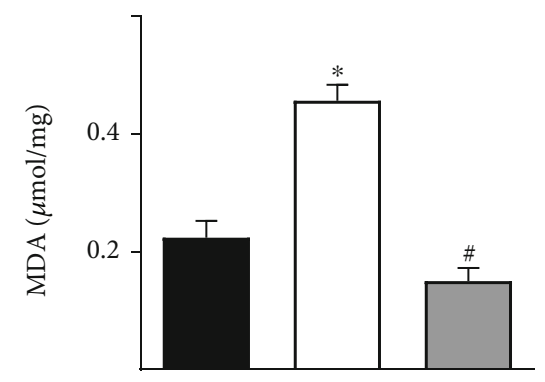

(a)

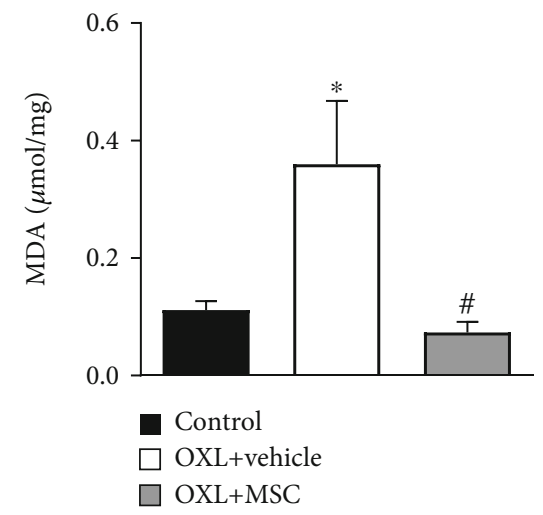

(c)

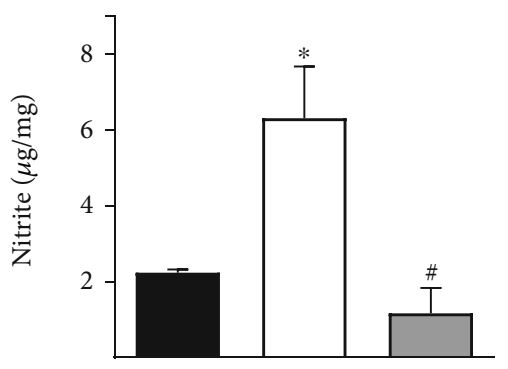

(b)

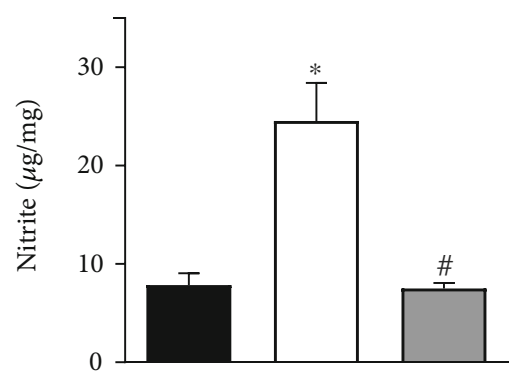

(d)

FIGURE 5: Effect of MSC on the levels of MDA and nitrite in the sciatic nerves and dorsal root ganglia of mice with OXL-induced chronic neuropathy. Two weeks after the OIPN model induction, mice were treated with $1 \times 10^{6} \mathrm{MSC}(\mathrm{OXL}+\mathrm{MSC})$ or vehicle (OXL+vehicle) by endovenous route. Control group received 5\% dextrose instead of OXL. The levels of MDA and nitrite in the sciatic nerve (a, b, respectively) and DRG (c, d, respectively) were measured 4 weeks after treatment. Data are expressed as means \pm standard deviation; $n=6$ mice per group. ${ }^{*}$ Statistical significance relative to the control group $(p<0.01) ;{ }^{*}$ statistical significance relative to the OXL+vehicle group $(p<0.001)$, as determined by one-way ANOVA followed by Tukey’s multiple comparison test.

organelle [11]. Importantly, the present study showed that MSC transplantation reduced mitochondrial atypia in primary afferent neurons of mice with OXL-induced neuropathy. Thus, it is possible that the antinociceptive effect induced by MSC during OIPN results in part from its ability to normalize mitochondria function in peripheral nociceptive neurons.

It is well established that the potential of MSC for tissue repair depends on various mechanisms, ranging from the secretion of paracrine factors and extracellular vesicles [66, 67] to the transfer of cellular organelles [68], such as mitochondria. Mitochondrial transfer between MSC and various cell types, including neural cells, has been well documented $[36,37,69,70]$. It has been proposed that cell damage acts as signaling for the directional transfer of mitochondria from MSC to damaged cells, and this seems to be a key mechanism for tissue repair mediated by these cells [33]. Recently, it has been proposed that this mechanism may be important for the therapeutic effects of MSC during cisplatin-induced neuropathy [29]. This hypothesis was not evaluated in the present study but will be the subject of future investigations.

It has been proposed that sensory alterations associated with neuropathy induced by platinum compounds originate from mitochondrial damage in peripheral sensory neurons, leading to increased production of reactive oxygen species (ROS), oxidative/nitrosative stress, and energy imbalance in these neurons $[71,72]$. The peripheral nervous system is more susceptible to oxidative stress due to the high phospholipid content and weak cellular antioxidant defenses and therefore is vulnerable to the mitotoxic effects of ROS induced by OXL $[64,73]$. In OIPN mice, in addition to the ultrastructural analysis revealing mitochondrial morphological damage in nociceptive primary afferent, the dearrangement of oxidative machinery in the peripheral nervous system was evidenced by the mismatch between high expression of oxidative stress markers and the mobilization of cellular antioxidant systems. Although the levels of nitrosative species and malondialdehyde in the peripheral nervous system of mice with OIPN were strongly elevated, the cellular antioxidant systems were apparently not activated, as indicated by the low expression of Sod and Nrf2 in the tissue. Activation of cellular antioxidant defenses is fundamental for the maintenance of redox homeostasis [74]. Mitochondria typically produce superoxide as part of the oxidative phosphorylation process, which is converted into hydrogen peroxide via superoxide dismutase and then to a highly toxic hydroxyl radical. Under normal conditions, the level of intracellular ROS is regulated by excessive ROS removal through enzymatic reactions, which convert ROS to harmless nonradicals. However, excessive ROS may accumulate intracellularly in nonphysiological situations of overproduction or impairment of removal. Under oxidative stress conditions, $N r f 2$ is activated and neutralizes ROS via upregulation of transcriptional antioxidant enzymes, such as Sod [75]. 
In this work the increase in nitric oxide levels and lipoperoxidation products was observed, parallel to the low Sod and $\mathrm{Nrf2}$ expression, in peripheral sensory neurons of mice with OIPN, evidencing that antioxidant defenses become inefficient during chronic neuropathy. This imbalance of the redox homeostasis, associated with OXL-induced mitochondrial dysfunction, creates a vicious cycle of energy dysregulation in peripheral sensory neurons, culminating in chronic painful neuropathy. In fact, the association of elevation of MDA and suppression of Nrf2 with OXL-induced peripheral neuropathy was previously proposed by Yang et al. [63], indicating that the Nrf2 signaling system is a protection mechanism against OIPN. Under conditions of persistent stress induced by OXL, DRG cells produce excessive amounts of ROS, which saturate the antioxidant system and therefore cause the failure of the adaptive antioxidant response, inducing oxidative damage to the peripheral nervous system. In this previous work, the authors pointed out that the activation of the Nrf2 system, before the OIPN development or in its early stages, prevents the ROS-induced damage and stops the progression of peripheral neuropathy. A study conducted by Yehia et al. [76] evidenced that this concept is also true in a clinical setting. The prophylactic effect of L-carnosine against the acute OXL neurotoxicity in colorectal cancer patients was investigated. In L-carnosine-treated patients, an improvement in the sensory neuropathy was associated with increased Nrf2 expression and reduced lipid peroxidation in serum samples. Here, we showed that the transplantation of MSC in OIPN mice also regulated the antioxidant system by increasing the expression of Sod and $\mathrm{Nrf2}$, reducing the levels of oxidative products in the nervous tissues. The present results highlight the role of MSC in correcting redox imbalances in the peripheral nervous system. It has been described that Nrf2 activation influences mitochondrial biogenesis [77, 78], especially under stress conditions, which may be especially relevant during OIPN, which has OXL-induced mitotoxicity as a central pathophysiological component. Thus, it is possible that the upregulation of Nrf2 is an important mechanism by which MSC induce a long-lasting antinociceptive effect during OIPN.

\section{Conclusions}

Altogether, these results indicate that the antioxidant properties of MSC mediated by Nrf2, combined with its ability to restore mitochondrial homeostasis, even after prolonged exposure to damage, may contribute to reversal of painful neuropathy induced by OXL. Several lines of evidence have indicated that the antinociceptive effect of MSC during painful neuropathies may depend on multiple mechanisms, which include activation of analgesic endogenous pathways, neuromodulation, immune regulation, and regenerative effects on the peripheral nerve. The present work provides evidence for a new mechanistic hypothesis to explain the long-lasting antinociceptive effects of MSC during chronic painful neuropathies, which is based on the ability of MSC to promote the restoration of mitochondria function and redox homeostasis in the nociceptive primary afferent.

\section{Data Availability}

The behavioral, biochemical, and electron microscopy data used to support the findings of this study are available from the corresponding author upon request.

\section{Disclosure}

The funding sponsors had no role in the design of the study; in the collection, analyses, or interpretation of the data; in the writing of the manuscript; and in the decision to publish the results.

\section{Conflicts of Interest}

The authors declare that there is no conflict of interest regarding the publication of this paper.

\section{Acknowledgments}

We are grateful for the support from the Print FiocruzCAPES Program. This work was supported by the Fundação de Amparo à Pesquisa do Estado da Bahia (FAPESB; grant number RED0010/2012). This study was financed in part by the Coordenação de Aperfeiçoamento de Pessoal de Nível Superior (CAPES), Brasil (Finance Code 001).

\section{References}

[1] C. R. Culy, D. Clemett, and L. R. Wiseman, "Oxaliplatin. A review of its pharmacological properties and clinical efficacy in metastatic colorectal cancer and its potential in other malignancies," Drugs, vol. 60, no. 4, pp. 895-924, 2000.

[2] R. Oun, Y. E. Moussa, and N. J. Wheate, "The side effects of platinum-based chemotherapy drugs: a review for chemists," Dalton Transactions, vol. 47, no. 19, pp. 6645-6653, 2018.

[3] P. M. Hoff, E. D. Saad, F. Costa et al., "Literature review and practical aspects on the management of oxaliplatinassociated toxicity," Colorectal Cancer, vol. 11, no. 2, pp. 93$100,2012$.

[4] E. Y. Ibrahim and B. E. Ehrlich, "Prevention of chemotherapyinduced peripheral neuropathy: a review of recent findings," Critical Reviews in Oncology/Hematology, vol. 145, p. 102831, 2020.

[5] G. Cavaletti, G. Tredici, M. G. Petruccioli et al., "Effects of different schedules of oxaliplatin treatment on the peripheral nervous system of the rat," European Journal of Cancer, vol. 37, no. 18, pp. 2457-2463, 2001.

[6] L. Di Cesare Mannelli, A. Pacini, L. Bonaccini, M. Zanardelli, T. Mello, and C. Ghelardini, "Morphologic features and glial activation in rat oxaliplatin-dependent neuropathic pain," The Journal of Pain, vol. 14, no. 12, pp. 1585-1600, 2013.

[7] R. W. Gregg, J. M. Molepo, V. J. A. Monpetit et al., "Cisplatin neurotoxicity: the relationship between dosage, time, and platinum concentration in neurologic tissues, and morphologic evidence of toxicity," Journal of Clinical Oncology, vol. 10, no. 5, pp. 795-803, 1992.

[8] D. Screnci, M. J. McKeage, P. Galettis, T. W. Hambley, B. D. Palmer, and B. C. Baguley, "Relationships between hydrophobicity, reactivity, accumulation and peripheral nerve toxicity of 
a series of platinum drugs," Journal of the Peripheral Nervous System, vol. 5, no. 2, pp. 117-118, 2000.

[9] V. Brabec and J. Kasparkova, "Modifications of DNA by platinum complexes: relation to resistance of tumors to platinum antitumor drugs," Drug Resistance Updates, vol. 8, no. 3, pp. 131-146, 2005.

[10] S. Quasthoff and H. P. Hartung, "Chemotherapy-induced peripheral neuropathy," Journal of Neurology, vol. 249, no. 1, pp. 9-17, 2002.

[11] A. Areti, V. G. Yerra, V. G. M. Naidu, and A. Kumar, "Oxidative stress and nerve damage: role in chemotherapy induced peripheral neuropathy," Redox Biology, vol. 2, pp. 289-295, 2014.

[12] A. Canta, E. Pozzi, and V. A. Carozzi, "Mitochondrial dysfunction in chemotherapy-induced peripheral neuropathy (CIPN)," Toxics, vol. 3, no. 2, pp. 198-223, 2015.

[13] M. R. Kelley, Y. Jiang, C. Guo, A. Reed, H. Meng, and M. R. Vasko, "Role of the DNA base excision repair protein, APE1 in cisplatin, oxaliplatin, or carboplatin induced sensory neuropathy," PLoS One, vol. 9, article e106485, 2014.

[14] H. Starobova and I. Vetter, "Pathophysiology of chemotherapy-induced peripheral neuropathy," Frontiers in Molecular Neuroscience, vol. 10, pp. 1-21, 2017.

[15] R. Zajączkowska, M. Kocot-Kępska, W. Leppert, A. Wrzosek, J. Mika, and J. Wordliczek, "Mechanisms of chemotherapyinduced peripheral neuropathy," International Journal of Molecular Sciences, vol. 20, article 1451, 2019.

[16] H. Zheng, W. H. Xiao, and G. J. Bennett, "Functional deficits in peripheral nerve mitochondria in rats with paclitaxel- and oxaliplatin-evoked painful peripheral neuropathy," Experimental Neurology, vol. 232, no. 2, pp. 154-161, 2011.

[17] D. L. Hershman, C. Lacchetti, R. H. Dworkin et al., "Prevention and management of chemotherapy-induced peripheral neuropathy in survivors of adult cancers: American Society of Clinical Oncology clinical practice guideline," Journal of Clinical Oncology, vol. 32, no. 18, pp. 1941-1967, 2014.

[18] S. T. Kim, Y. H. Chung, H. S. Lee et al., "Protective effects of phosphatidylcholine on oxaliplatin-induced neuropathy in rats," Life Sciences, vol. 130, pp. 81-87, 2015.

[19] K. F. Al-Massri, L. A. Ahmed, and H. S. El-Abhar, "Mesenchymal stem cells in chemotherapy-induced peripheral neuropathy: a new challenging approach that requires further investigations," Journal of Tissue Engineering and Regenerative Medicine, vol. 14, pp. 108-122, 2019.

[20] L. Chen, H. Huang, H. S. Sharma, H. Zuo, and P. R. Sanberg, "Cell transplantation as a pain therapy targets both analgesia and neural repair," Cell Transplantation, vol. 22, no. 1, pp. 11-19, 2013.

[21] Y. Huh, R. R. Ji, and G. Chen, "Neuroinflammation, bone marrow stem cells, and chronic pain," Frontiers in Immunology, vol. 21, no. 8, article 1014, 2017.

[22] A. T. Brini, G. Amodeo, L. M. Ferreira et al., "Therapeutic effect of human adipose-derived stem cells and their secretome in experimental diabetic pain," Scientific Reports, vol. 7, no. 1, p. 9904, 2017.

[23] A. F. Evangelista, M. A. Vannier-Santos, G. S. de Assis Silva et al., "Bone marrow-derived mesenchymal stem/stromal cells reverse the sensorial diabetic neuropathy via modulation of spinal neuroinflammatory cascades," Journal of Neuroinflammation, vol. 15, no. 1, p. 189, 2018.

[24] E. T. Guimarães, G. S. Cruz, T. F. Almeida et al., “Transplantation of stem cells obtained from murine dental pulp improves pancreatic damage, renal function, and painful diabetic neuropathy in diabetic type 1 mouse model," Cell Transplantation, vol. 22, no. 12, pp. 2345-2354, 2013.

[25] S. Franchi, A. E. Valsecchi, E. Borsani et al., "Intravenous neural stem cells abolish nociceptive hypersensitivity and trigger nerve regeneration in experimental neuropathy," Pain, vol. 153, no. 4, pp. 850-861, 2012.

[26] K. B. Gama, D. S. Santos, A. F. Evangelista et al., "Conditioned medium of bone marrow-derived mesenchymal stromal cells as a therapeutic approach to neuropathic pain: a preclinical evaluation," Stem Cells International, vol. 2018, Article ID 8179013, 12 pages, 2018.

[27] D. Siniscalco, C. Giordano, U. Galderisi et al., "Long-lasting effects of human mesenchymal stem cell systemic administration on pain-like behaviors, cellular, and biomolecular modifications in neuropathic mice," Frontiers in Integrative Neuroscience, vol. 5, 2011.

[28] S. Watanabe, K. Uchida, H. Nakajima et al., "Early transplantation of mesenchymal stem cells after spinal cord injury relieves pain hypersensitivity through suppression of painrelated signaling cascades and reduced inflammatory cell recruitment," Stem Cells, vol. 33, no. 6, pp. 1902-1914, 2015.

[29] N. Boukelmoune, G. S. Chiu, A. Kavelaars, and C. J. Heijnen, "Mitochondrial transfer from mesenchymal stem cells to neural stem cells protects against the neurotoxic effects of cisplatin," Acta Neuropathologica Communications, vol. 6, no. 1, p. 139, 2018.

[30] L. Di Cesare Mannelli, B. Tenci, L. Micheli et al., "Adiposederived stem cells decrease pain in a rat model of oxaliplatininduced neuropathy: role of VEGF-A modulation," Neuropharmacology, vol. 131, pp. 166-175, 2018.

[31] I. O. Sherif, D. Sabry, A. Abdel-Aziz, and O. M. Sarhan, "The role of mesenchymal stem cells in chemotherapy-induced gonadotoxicity," Stem Cell Research \& Therapy, vol. 9, no. 1, p. 196, 2018.

[32] H. Liu, S. J. McTaggart, D. W. Johnson, and G. C. Gobe, “Antioxidant pathways are stimulated by mesenchymal stromal cells in renal repair after ischemic injury," Cytotherapy, vol. 14, no. 2, pp. 162-172, 2012.

[33] M. Mahrouf-Yorgov, L. Augeul, C. C. Da Silva et al., "Mesenchymal stem cells sense mitochondria released from damaged cells as danger signals to activate their rescue properties," Cell Death and Differentiation, vol. 24, no. 7, pp. 1224-1238, 2017.

[34] A. Valle-Prieto and P. A. Conget, "Human mesenchymal stem cells efficiently manage oxidative stress," Stem Cells and Development, vol. 19, no. 12, pp. 1885-1893, 2010.

[35] M. A. El-Far, M. M. Gabr, S. M. El-Halawani et al., "Novel evidence of restoring and augmenting antioxidant defense after treatment of diabetic rats using stem cells," Current Topics in Biochemical Research, vol. 14, pp. 25-37, 2012.

[36] T. Ahmad, S. Mukherjee, B. Pattnaik et al., "Miro1 regulates intercellular mitochondrial transport \& enhances mesenchymal stem cell rescue efficacy," The EMBO Journal, vol. 33, pp. 994-1010, 2014.

[37] V. A. Babenko, D. N. Silachev, V. A. Popkov et al., "Miro1 enhances mitochondria transfer from multipotent mesenchymal stem cells (MMSC) to neural cells and improves the efficacy of cell recovery," Molecules, vol. 23, no. 3, p. 687, 2018.

[38] S. Paliwal, R. Chaudhuri, A. Agrawal, and S. Mohanty, "Human tissue-specific MSCs demonstrate differential mitochondria transfer abilities that may determine their 
regenerative abilities," Stem Cell Research \& Therapy, vol. 9, no. 1, pp. 298-299, 2018.

[39] J. L. Spees, S. D. Olson, M. J. Whitney, and D. J. Prockop, "Mitochondrial transfer between cells can rescue aerobic respiration," Proceedings of the National Academy of Sciences of the United States of America, vol. 103, no. 5, pp. 1283-1288, 2006.

[40] J. Wang, H. Li, Y. Yao et al., "Stem cell-derived mitochondria transplantation: a novel strategy and the challenges for the treatment of tissue injury," Stem Cell Research \& Therapy, vol. 9, no. 1, pp. 106-110, 2018.

[41] N. Kiguchi, Y. Kobayashi, Y. Kadowaki, Y. Fukazawa, F. Saika, and S. Kishioka, "Vascular endothelial growth factor signaling in injured nerves underlies peripheral sensitization in neuropathic pain," Journal of Neurochemistry, vol. 129, no. 1, pp. 169-178, 2014.

[42] K. Maiese, "Novel applications of trophic factors, wnt and wisp for neuronal repair and regeneration in metabolic disease," Neural Regeneration Research, vol. 10, no. 4, pp. 518-528, 2015.

[43] J. Wang, J. Yu, C. P. Ding, S. P. Han, X. Y. Zeng, and J. Y. Wang, "Transforming growth factor-beta in the red nucleus plays antinociceptive effect under physiological and pathological pain conditions," Neuroscience, vol. 291, pp. 37-45, 2015.

[44] M. Soleimani and S. Nadri, "A protocol for isolation and culture of mesenchymal stem cells from mouse bone marrow," Nature Protocols, vol. 4, no. 1, pp. 102-106, 2009.

[45] M. I. Azevedo, A. F. Pereira, R. B. Nogueira et al., "The antioxidant effects of the flavonoids rutin and quercetin inhibit oxaliplatin-induced chronic painful peripheral neuropathy," Molecular Pain, vol. 9, pp. 1744-8069, 2013.

[46] S. R. Chaplan, F. W. Bach, J. W. Pogrel, J. M. Chung, and T. L. Yaksh, "Quantitative assessment of tactile allodynia in the rat paw," Journal of Neuroscience Methods, vol. 53, no. 1, pp. 55-63, 1994.

[47] L. E. Ta, J. D. Schmelzer, A. J. Bieber et al., "A novel and selective poly (ADP-ribose) polymerase inhibitor ameliorates chemotherapy-induced painful neuropathy," PLoS One, vol. 8, article e54161, 2013.

[48] W. J. Dixon, "Efficient analysis of experimental observations," Annual Review of Pharmacology and Toxicology, vol. 20, no. 1, pp. 441-462, 1980.

[49] G. G. L. dos Santos, L. L. C. e Silva, M. B. P. Soares, and C. F. Villarreal, "Antinociceptive properties of Micrurus lemniscatus venom," Toxicon, vol. 60, no. 6, pp. 1005-1012, 2012.

[50] N. L. M. Quintão, R. Medeiros, A. R. S. Santos, M. M. Campos, and J. B. Calixto, "The effects of diacerhein on mechanical allodynia in inflammatory and neuropathic models of nociception in mice," Anesthesia and Analgesia, vol. 101, pp. 1763-1769, 2005.

[51] S. J. L. Flatters and G. J. Bennett, "Studies of peripheral sensory nerves in paclitaxel-induced painful peripheral neuropathy: evidence for mitochondrial dysfunction," Pain, vol. 122, no. 3, pp. 245-257, 2006.

[52] E. S. Santos, L. S. Aragão-França, C. S. Meira et al., "Tolerogenic dendritic cells reduce cardiac inflammation and fibrosis in chronic Chagas disease," Frontiers in Immunology, vol. 11, p. $488,2020$.

[53] T. D. Schmittgen and K. J. Livak, "Analyzing real-time PCR data by the comparative $\mathrm{C}_{\mathrm{T}}$ method," Nature Protocols, vol. 3, no. 6, pp. 1101-1108, 2008.

[54] V. Tiwari, A. Kuhad, and K. Chopra, "Tocotrienol ameliorates behavioral and biochemical alterations in the rat model of alcoholic neuropathy," Pain, vol. 145, no. 1, pp. 129-135, 2009.
[55] L. C. Green, D. A. Wagner, J. Glogowski, P. L. Skipper, J. S. Wishnok, and S. R. Tannenbaum, "Analysis of nitrate, nitrite, and $\left[{ }^{15} \mathrm{~N}\right]$ nitrate in biological fluids," Analytical Biochemistry, vol. 126, pp. 131-138, 1982.

[56] P. Kokotis, M. Schmelz, E. Kostouros, N. Karandreas, and M. A. Dimopoulos, "Oxaliplatin-induced neuropathy: a longterm clinical and neurophysiologic follow-up study," Colorectal Cancer, vol. 15, no. 3, pp. e133-e140, 2016.

[57] S. B. Park, C. S. Y. Lin, A. V. Krishnan, D. Goldstein, M. L. Friedlander, and M. C. Kiernan, "Oxaliplatin-induced neurotoxicity: changes in axonal excitability precede development of neuropathy," Brain, vol. 132, no. 10, pp. 2712-2723, 2009.

[58] U. Schlegel, "Central nervous system toxicity of chemotherapy," European Association of NeuroOncology Magazine, vol. 1, pp. 25-29, 2011.

[59] W. Grisold, S. Oberndorfer, and A. J. Windebank, "Chemotherapy and polyneuropathies," European Association of NeuroOncology Magazine, vol. 2, pp. 25-36, 2012.

[60] S. Asgharzade, A. Talaei, T. Farkhondeh, and F. Forouzanfar, "A review on stem cell therapy for neuropathic pain," Current Stem Cell Research \& Therapy, vol. 15, no. 4, pp. 349-361, 2020.

[61] K. Chakravarthy, Y. Chen, C. He, and P. J. Christo, "Stem cell therapy for chronic pain management: review of uses, advances, and adverse effects," Pain Physician, vol. 20, no. 4, pp. 293-305, 2017.

[62] G. G. L. dos Santos, A. L. L. Oliveira, D. S. Santos et al., "Mesenchymal stem cells reduce the oxaliplatin-induced sensory neuropathy through the reestablishment of redox homeostasis in the spinal cord," Life Sciences, vol. 265, no. article 118755, 2020.

[63] Y. Yang, L. Luo, X. Cai et al., "Nrf2 inhibits oxaliplatininduced peripheral neuropathy via protection of mitochondrial function," Free Radical Biology \& Medicine, vol. 120, pp. 13-24, 2018.

[64] W. H. Xiao and G. J. Bennett, "Effects of mitochondrial poisons on the neuropathic pain produced by the chemotherapeutic agents, paclitaxel and oxaliplatin," Pain, vol. 153, no. 3, pp. 704-709, 2012.

[65] J. Podratz, A. Schlattau, B. Chen, A. Knight, and A. Windebank, "Platinum adduct formation in mitochondrial DNA may underlie the phenomenon of coasting," Journal of the Peripheral Nervous System, vol. 12, 2007.

[66] C. P. K. Lai and X. O. Breakefield, "Role of exosomes/microvesicles in the nervous system and use in emerging therapies," Frontiers in Physiology, vol. 3, 2012.

[67] X. Liang, Y. Ding, Y. Zhang, H. F. Tse, and Q. Lian, "Paracrine mechanisms of mesenchymal stem cell-based therapy: current status and perspectives," Cell Transplantation, vol. 23, no. 9, pp. 1045-1059, 2014.

[68] D. Torralba, F. Baixauli, and F. Sánchez-Madrid, "Mitochondria know no boundaries: mechanisms and functions of intercellular mitochondrial transfer," Frontiers in Cell and Development Biology, vol. 4, 2016.

[69] V. A. Babenko, D. N. Silachev, L. D. Zorova et al., "Improving the post-stroke therapeutic potency of mesenchymal multipotent stromal cells by cocultivation with cortical neurons: the role of crosstalk between cells," Stem Cells Translational Medicine, vol. 4, no. 9, pp. 1011-1020, 2015.

[70] K. Hayakawa, E. Esposito, X. Wang et al., “Transfer of mitochondria from astrocytes to neurons after stroke," Nature, vol. 535, no. 7613, pp. 551-555, 2016. 
[71] K. Janes, T. Doyle, L. Bryant et al., "Bioenergetic deficits in peripheral nerve sensory axons during chemotherapyinduced neuropathic pain resulting from peroxynitritemediated post-translational nitration of mitochondrial superoxide dismutase," Pain, vol. 154, no. 11, pp. 2432-2440, 2013.

[72] W. H. Xiao, H. Zheng, F. Y. Zheng, R. Nuydens, T. F. Meert, and G. J. Bennett, "Mitochondrial abnormality in sensory, but not motor, axons in paclitaxel-evoked painful peripheral neuropathy in the rat," Neuroscience, vol. 199, pp. 461-469, 2011.

[73] A. A. Argyriou, J. Bruna, P. Marmiroli, and G. Cavaletti, "Chemotherapy-induced peripheral neurotoxicity (CIPN): an update," Critical Reviews in Oncology/Hematology, vol. 82, no. 1, pp. 51-77, 2012.

[74] D. Trachootham, W. Lu, M. A. Ogasawara, R. D. Nilsa, and P. Huang, "Redox regulation of cell survival," Antioxidants \& Redox Signaling, vol. 10, no. 8, pp. 1343-1374, 2008.

[75] A. T. Dinkova-Kostova and A. Y. Abramov, "The emerging role of Nrf2 in mitochondrial function," Free Radical Biology \& Medicine, vol. 88, Part B, pp. 179-188, 2015.

[76] R. Yehia, S. Saleh, H. El Abhar, A. S. Saad, and M. Schaalan, "LCarnosine protects against oxaliplatin-induced peripheral neuropathy in colorectal cancer patients: a perspective on targeting Nrf- 2 and NF- $\kappa \mathrm{B}$ pathways," Toxicology and Applied Pharmacology, vol. 365, pp. 41-50, 2019.

[77] G. Negi, A. Kumar, and S. S. Sharma, "Nrf2 and NF- $\kappa$ B modulation by Sulforaphane counteracts multiple manifestations of diabetic neuropathy in rats and high glucose-induced changes," Current Neurovascular Research, vol. 8, no. 4, pp. 294-304, 2011.

[78] Y. Shi, X. C. Liang, H. Zhang, Q. L. Wu, L. Qu, and Q. Sun, "Quercetin protects rat dorsal root ganglion neurons against high glucose-induced injury in vitro through Nrf-2/HO-1 activation and NF- $\kappa$ B inhibition," Acta Pharmacologica Sinica, vol. 34, no. 9, pp. 1140-1148, 2013. 